\title{
A experiência do Gabinete Digital \\ do Estado do Rio Grande do Sul e a construção da cibercidadania no Brasil
}

\author{
The experience of the Digital Office of State of \\ Rio Grande do Sul and the construction of cyber \\ citizenship in Brazil
}

\author{
Letícia Bodanese Rodegheri* \\ Rafael Santos de Oliveira*
}

\section{Resumo}

A internet constitui-se em um meio dinâmico, de fácil e rápido acesso, que pode contribuir, além das trocas de informações, produtos e serviços, para a construção da cibercidadania. Há o interesse, tanto por parte dos governos como dos cidadãos, em utilizá-la como local de encontro, debate e fortalecimento da cidadania. O presente trabalho objetiva verificar se a experiência do Gabinete Digital do Estado do Rio Grande do Sul vem sendo seguida por outros lugares, com a disponibilização de espaços para interatividade entre os cidadãos e o governo. Para tanto, empregou-se o método de abordagem dedutivo, partindo da conceituação de cidadania de T. H. Marshall e do que vem disposto na Constituição Federal de 1988 para, em um segundo momento, analisar o referido portal. Também foi realizada uma observação sistemática, direta e não participativa em nove portais de municípios, estados e de um instituto federal, divididos em quatro categorias, com a principal finalidade de examinar se existe essa interatividade. Conclui-se que as iniciativas ainda são incipientes e na maioria dos casos não há possibilidade de contato direto entre cidadãos e governo.

Mestranda em Direito pela Universidade Federal de Santa Maria - Linha de Pesquisa Direitos da Sociedade em Rede. Graduada em Direito pela Universidade Federal de Santa Maria. Integrante do Núcleo de Direito Informacional (NUDI). Santa Maria - RS - Brasil. E-mail: leticiabrodegheri@ gmail.com.

* Doutor em Direito pela Universidade Federal de Santa Catarina (UFSC). Professor Adjunto no Departamento de Direito da Universidade Federal de Santa Maria (UFSM). Santa Maria - RS Brasil. E-mail: advrso@gmail.com. 
Palavras-chave: Cidadania. Tecnologias da informação e comunicação. Cibercidadania. Interatividade. Gabinete Digital do Estado do Rio Grande do Sul.

\section{Abstract}

The Internet has a dynamic, easy and quick access, which may contribute, in addition to the exchange of information, products and services for the construction of cyber citizenship. There is the interest of governments and citizens to use the web as a meeting place for discussion and thus strengthening citizenship. This study aims to verify if the experience of the Digital Office of state of Rio Grande do Sul has been followed by other places, with the provision of spaces for interactivity between citizens and government. It is used the deductive method of approach, based on the concept of citizenship of T. H. Marshall and in the Federal Constitution of 1988 to, in a second step, analyze the mentioned portal. Also, it was conducted an observation systematic, direct and non-participative in nine portals of cities, states and in a federal institute, divided into four categories, with the main purpose to examine whether this interactivity exists. It is concluded that the initiatives are still incipient and, in most cases, there is no possibility of direct contact between citizens and government.

Keywords: Citizenship. Information and communication technologies. Cyber citizenship. Interactivity. Digital Office of State of Rio Grande do Sul.

\section{Introdução}

A cidadania não pode ser considerada, em um mundo globalizado e em constante interação, como o simples direito de votar e ser votado. Para permitir esse repensar, é necessário invocar o ensaio do sociólogo T. H. Marshall, "Cidadania e classe social", que aborda o conceito de cidadania como um conjunto formado por aspectos civis, políticos e sociais que devem ser atendidos.

Como forma de aproximar a população dos governos e reavivar essa conceituação trazida por Marshall, a internet tem se revelado um ambiente propício para debates, intercâmbio de informações e 
manifestação dos cidadãos para a adoção de políticas públicas mais efetivas aos seus anseios.

Facilidades como rapidez, instantaneidade, não existência de filtros prévios para as publicações, bem como a transposição de barreiras temporais e territoriais, têm mostrado um lado muito positivo da internet: a possibilidade de construção de uma cibercidadania, em que o cidadão, bem informado e atento aos acontecimentos do seu município, estado ou país, pode colaborar para que as suas necessidades sejam tomadas como prioridades pelos governos.

Por isso, o presente artigo objetiva verificar se a experiência do Gabinete Digital do Estado do Rio Grande do Sul tem sido difundida para outros lugares. Diante disso, questiona-se: quais são os limites e as possibilidades de replicação desse modelo no que concerne ao contato direto entre cidadãos e governantes, de forma on-line? Escolheu-se a experiência gaúcha como parâmetro para a pesquisa por ser uma iniciativa local e ter-se visualizado a utilização das ferramentas constantes no portal com dinâmica e relacionando-se com assuntos atuais, como a proposição de debates on-line sobre a reforma política1.

Para tanto, empregou-se o método de abordagem dedutivo, que em um primeiro momento tratou de conceitos acerca da cidadania, tendo como teoria de base a conceituação de T. H. Marshall, para chegar até o caso concreto de análise do portal do Gabinete Digital. Nesse segundo momento, foi realizada uma pesquisa durante o mês de junho de 2013 para sistematizar outras iniciativas semelhantes e dividilas em categorias, de acordo com a existência ou não de interatividade governo-sociedade, com apenas um site como complemento às iniciativas presenciais ou, ainda, com a adoção de medidas específicas

\footnotetext{
O debate sobre a reforma política no Brasil foi suscitado, entre outras razões, pela onda de manifestações ocorridas no país durante os meses de junho e julho de 2013. As manifestações, que inicialmente previam a redução das tarifas de ônibus, passaram a tratar de outros assuntos de interesse geral, que pressionaram o governo a tomar providências e atender aos reclames da população.
} 
e temporárias. A observação dos dez portais analisados se deu de forma sistemática, direta e não participativa.

O trabalho foi dividido em dois tópicos centrais. No primeiro, abordou-se o conceito de cidadania sob a perspectiva de T. H. Marshall e a sistematização desse direito na Constituição Federal de 1988. Diante do processo de globalização e da larga utilização das Tecnologias de Informação e Comunicação (TICs), tratou-se das peculiaridades da internet que incentivam a formação de uma cibercidadania. No segundo tópico, o objeto da análise centrou-se no Gabinete Digital do Estado do Rio Grande do Sul e, posteriormente, na observação de outros nove portais de municípios, estados e de um instituto federal, procurando-se formas de contato direto entre os cidadãos e os governos.

\section{Da cidadania à cibercidadania}

O termo "cidadania" aparece na Constituição Federal de 1988 já no artigo $1^{\circ}$, inciso II, em que há a descrição da formação da República Federativa do Brasil - união indissolúvel dos estados, municípios e do Distrito Federal -, constituindo-se em um Estado Democrático de Direito, que tem como um de seus fundamentos a cidadania. No parágrafo único do referido artigo, sustenta-se que "todo o poder emana do povo, que o exerce por meio de representantes eleitos ou diretamente, nos termos desta Constituição" (BRASIL, 1988).

Na sequência, o vocábulo consta no artigo $5^{\circ}$, inciso $L X X I$, que se refere ao mandado de injunção, e inciso LXXVII, que trata da gratuidade das ações de habeas corpus e habeas data; no artigo 22, inciso XIII, que dispõe sobre competência privativa da União para legislar sobre cidadania, nacionalidade e naturalização; no artigo $62, \S 1^{\circ}$, inciso I, alínea "a", que veda a edição de medidas provisórias sobre cidadania, nacionalidade, direitos políticos, partidos políticos e direito eleitoral; no artigo $68, \S 1^{\circ}$, inciso II, que veda a elaboração de leis delegadas sobre cidadania, entre outros; bem como no artigo 205, referente à educação, como sendo um direito de todos e um dever do Estado e da família, 
que deve visar o pleno desenvolvimento da pessoa, o preparo para o exercício da cidadania e qualificação para o trabalho (BRASIL, 1988).

Depreende-se do texto constitucional que o termo "cidadania" está vinculado, em um primeiro momento, a um sentido mais amplo do que o de titular de direitos políticos, pois qualifica os participantes da vida do Estado, aos quais deve ser submetido o funcionamento deste. Isso quer dizer que, para o bom desenvolvimento do Estado, é necessária a manifestação da vontade popular, a qual consiste em um "[...] atributo político decorrente do direito de participar no governo e direito de ser ouvido pela representação política" (SILVA, 2009, p. 346).

Especificamente, cidadão é o indivíduo que é titular dos direitos políticos de votar e ser votado, os quais apresentam como pressuposto a nacionalidade, pois somente pode ser cidadão aquele que for titular da nacionalidade brasileira. Está, portanto, diretamente relacionado ao próprio artigo $1^{\circ}$, bem como ao artigo 14 , ambos da Constituição Federal. No último, verifica-se que o exercício da soberania nacional está ligado ao sufrágio universal, quer dizer, ao voto direto e secreto, com igual valor para todos² (BRASIL, 1988).

No entanto, a cidadania na sociedade contemporânea não pode ser vista apenas sob um viés relacionado aos direitos políticos. Para tanto, é imprescindível retomar o ensaio de T. H. Marshall, que, mesmo tendo sido publicado pela primeira vez em 1949, ainda continua a ser referencial teórico obrigatório para esse repensar.

Marshall divide o conceito de cidadania em três elementos (ou partes): civil, político e social. O primeiro é composto dos direitos necessários à liberdade individual, como a liberdade de ir e vir, de imprensa, de pensamento, direito à propriedade e à justiça, destacando-

2 É dessa relação que se estabelece o núcleo fundamental dos direitos políticos, como o direito eleitoral de votar e ser votado, a qual possibilita abarcar os direitos políticos em ativos e passivos: "São apenas modalidades do seu exercício ligadas à capacidade eleitoral ativa, consubstanciada nas condições do direito de votar, e à capacidade eleitoral passiva, que assenta na elegibilidade, atributo de quem preenche as condições do direito de ser votado. Os direitos políticos ativos (ou direito eleitoral ativo) cuidam do eleitor e sua atividade; os direitos políticos passivos (ou direito eleitoral passivo) referem-se aos elegíveis e aos eleitos." (SILVA, 2009, p. 346, grifo do autor). 
se a atuação dos tribunais de justiça. O elemento político remete ao direito de participar no exercício do poder político como membro de um organismo detentor de autoridade política - a exemplo do parlamento e dos conselhos do governo local - ou como um eleitor dos membros do referido órgão. Por fim, o elemento social refere-se "[...] a tudo o que vai desde o direito a um mínimo de bem-estar econômico e segurança ao direito de participar [...] na herança social e levar a vida de um ser civilizado de acordo com os padrões que prevalecem na sociedade" (MARSHALL, 1967, p. 63-64). Relaciona-se ao sistema educacional e aos serviços sociais.

Partindo dessa conceituação, o autor afirma que tais elementos, historicamente, estavam fundidos em um só. Como exemplo, cita que os direitos sociais do indivíduo faziam parte e originavam-se do mesmo status que determinava a espécie de justiça que receberia, bem como a maneira pela qual participaria da administração dos negócios da comunidade à qual pertencia (MARSHALL, 1967).

Todavia, deve-se salientar que esse status de "cidadão" difere do moderno conceito, porque se constituía em marca distintiva de classe e de desigualdade. Exemplificando, Dallari (2010) trata da posição peculiar que o indivíduo ocupava no Estado Grego. Explica que mesmo o Estado sendo considerado democrático, apenas uma faixa restrita da população - os chamados "cidadãos", ou seja, a elite - participava das decisões políticas. Essa situação era sustentada a fim de que se mantivessem as características da cidade-Estado, pois a ampliação excessiva do número de "cidadãos" tornaria inviável a manutenção do controle por um pequeno número - a chamada "classe política", composta por uma elite, com intensa participação nas decisões do Estado.

Seguindo com o curso da história, Marshall (1967) afirma que na sociedade medieval há exemplos de uma cidadania genuína, mas que os direitos e deveres eram estritamente locais, ao passo que a cidadania é, por definição, nacional, quer dizer, ligada ao Estado-nação. Na sequência, refere que tais elementos - civil, político e social - foram separando-se justamente em função de seu caráter nacional. 
No caso dos direitos políticos, a questão se cifrava ao direito de voto e à habilitação para candidatar-se ao Parlamento. No caso dos direitos civis, a matéria dependia da jurisdição dos vários tribunais, dos privilégios da profissão de advogado e, acima de tudo, a responsabilidade de arcar com as custas do litígio. (MARSHALL, 1967, p. 65-66).

Quanto aos direitos sociais, o foco de Marshall (1967) centrase em verificar o impacto da cidadania sobre a desigualdade social, motivo pelo qual considera a cidadania com um status concedido aos membros integrais de uma comunidade, os quais são iguais em direitos e obrigações. A classe social, por outro lado, constitui-se em um sistema de desigualdades, diretamente ligado à ascensão do capitalismo no século XX. Para o autor, há uma relação necessária pelo capitalismo vigente, que se estabelece entre a busca por igualdade - através da universalização da cidadania - e a manutenção de um sistema de desigualdades, produzido pelo próprio sistema capitalista.

O que se pretende demonstrar com a visão de Marshall (1967) é que o conceito de cidadania deve ser visto sob a perspectiva de inclusão de direitos civis (liberdade de expressão, de ir e vir, entre outros), políticos (direito de votar e ser votado) e sociais (bem-estar, segurança, educação, saúde, dentre outros).

Ademais, tem-se questionado o papel do cidadão em um mundo constantemente conectado, cujas interações acontecem em escala global, em que há crescente utilização das Tecnologias da Informação e Comunicação (TICs) e os processos de produção são flexíveis e ocorrem em diversas partes do mundo, havendo intervenção de empresas e agentes internacionais. A principal origem dessas transformações reside no fenômeno da globalização, o qual pode ser entendido como um "[...] vasto e intenso campo de conflitos entre grupos sociais, Estados e interesses hegemônicos, por um lado, e grupos sociais, Estados e interesses subalternos, por outro" (SANTOS, 2011 p. 27).

Em razão dessas alterações que vêm ocorrendo na sociedade moderna, há a necessidade de os Estados buscarem e criarem 
oportunidades para uma participação cada vez mais efetiva dos cidadãos, de modo que eles possam participar ativamente do processo democrático, o qual não deve ser encerrado apenas na possibilidade de votar e ser votado. As TICs, em especial a internet, surgem como uma ferramenta apta a incrementar a participação cidadã, cujas características peculiares tornam possível uma participação direta, rápida e conjunta com os demais indivíduos.

Dentre as características que diferenciam a internet dos demais meios de comunicação, há destaque para a informação, que não se manifesta de forma unidirecional, ou seja, do emissor para o receptor, mas de forma multilateral, quer dizer, entre vários indivíduos, e todos, ao mesmo tempo, podem receber e enviar informações. Com isso, qualquer um pode, a qualquer tempo e de qualquer lugar, desde que com acesso à rede, exprimir suas opiniões, as quais serão imediatamente acessadas e conhecidas por pessoas de todos os locais do mundo.

O ambiente propiciado pela internet cria formas de liberdade de expressão e comunicação jamais vivenciadas na sociedade contemporânea, pois o conteúdo ali alocado, em regra, não passa por prévios filtros de censura, como ocorre na mídia tradicional, a exemplo da televisão e do jornal. Por isso, a utilização da internet passou a difundir-se e a ganhar perspectivas inicialmente não previstas, pois cada vez mais os cibernautas agem ativamente no processo de produção e consumo de informações.

A atuação dos internautas em blogs, sites ou redes sociais on-line constitui uma forma de ação política organizada que utiliza a internet como veículo de propagação de ideologia e informações, buscando, dentre outros objetivos, a transformação da realidade, na medida em que "[...] alteram os processos de comunicação, de produção, de criação e de circulação de bens e serviços neste início do século XXI, trazendo uma nova configuração social, cultural, comunicacional e, consequentemente, política" (LEMOS; LEVY, 2010, p. 45).

Perante essa nova configuração política, favorece-se a prática da chamada cibercidadania, que pode ser entendida como o acesso 
à internet que vai muito além de consumir, informar ou procurar por bens e serviços. Trata-se da possibilidade de utilização do ambiente on-line para criar relações interpessoais sob uma perspectiva política, social e cívica. Em outras palavras, "cibercidadania é mais do que ter acesso à conectividade, é mais do que poder consumir online. É atuar no ciberespaço com perspectiva comunitária e política" (SILVA, 2013).

A cibercidadania pode ser tratada como uma exigência da sociedade moderna e informatizada, que procura não apenas obter informações e dados atualizados do Estado, como também prima por uma maior participação e contribuição na tomada de decisões, de modo que os interesses dos cidadãos também sejam considerados e as necessidades, atendidas.

Trata-se de um conceito que está diretamente ligado à noção de governo eletrônico, o qual, na visão de Lévy (1999, p. 22), objetiva a possibilidade de encorajar, através das possibilidades de comunicação interativa e coletiva proporcionadas pelo ciberespaço,

[...] a expressão e a elaboração dos problemas da cidade pelos próprios cidadãos, a auto-organização das comunidades locais, a participação nas deliberações por parte dos grupos diretamente afetados pelas decisões, a transparência das políticas públicas e sua avaliação pelos cidadãos.

Por isso, em uma sociedade informacional, destaca-se cada vez mais a atuação dos cidadãos de forma a pressionar e direcionar as opções políticas, produzindo resultados concretos que irão beneficiar a comunidade como um todo. Individualmente, ou por meio de grupos e associações, torna-se cada vez mais necessário o fomento de discussões e a aproximação da população com os Estados. Em um mundo globalizado, que vive e participa intensamente das mudanças que ocorrem a nível global, torna-se imperiosa a oitiva dos cidadãos e o conhecimento das demandas locais para que as políticas sejam empregadas com maior efetividade. 
A participação popular articulada em rede pode, cada vez mais, contribuir para a adoção de medidas que atuem diretamente nas carências da sociedade. Assim, as políticas implementadas pelos governos terão maior eficácia e, consequentemente, atenderão às necessidades da população, que, por sua vez, sentirá maior confiança tanto no Estado como na própria utilização da internet.

Castells (2003 p. 128) diz que a internet torna possível aos cidadãos solicitar informações, expressar opiniões e até pedir respostas pessoais aos representantes, de forma que, "em vez de o governo vigiar as pessoas, as pessoas poderiam estar vigiando o seu governo - o que de fato é um direito delas, já que teoricamente o povo é o soberano". No entanto, também afirma que, apesar de a internet deter um significativo potencial em termos de expressão dos cidadãos e de comunicação dos valores humanos, ela não pode substituir a mudança social nem a reforma política. Sua função reside em colocar as pessoas em uma ágora pública, a fim de manifestarem suas inquietações e esperanças.

Esse acesso às TICs pode ser tratado, inclusive, como uma forma de "empoderamento" (empowerment, em inglês) do cidadão, de modo a ampliar as possibilidades de controle, por um sujeito ou pela população como um todo, dos aspectos significativos relacionados à própria existência, uma vez que o acesso à informação e ao espaço virtual proporciona uma postura ativa ao internauta (SEN, 2011).

Essa postura ativa do cidadão é influenciada, em grande parte, pela capacidade que a internet possui de atrair uma diversidade de mensagens e participantes, aumentando a massa crítica e o valor das opiniões dos cibernautas. Formam-se, assim, agrupamentos de pessoas físicas e organizações que podem interagir com expressividade no que se tornou "[...] uma Teia de Alcance Mundial para comunicação individualizada, interativa" (CASTELLS, 1999, p. 439-440).

Com a atuação dos cidadãos e a disponibilização de espaço, pelos governos, para essas manifestações, é possível incentivar a multiplicação de locais de discussão e de manifestação de opiniões de populações, grupos e coletivos muitas vezes excluídos pelos meios 
tradicionais de comunicação (televisão, rádio, dentre outros), bem como promover experiências participativas, através das TICs, para o desenvolvimento de comunidades, cidades e até mesmo de países ${ }^{3}$.

Defende-se que a nova esfera pública necessita transformar o cidadão bem informado, produtor de informação e constantemente conectado à internet, em um cibercidadão ativista, engajado nas ações pela transformação dos antigos espaços em locais públicos de memórias ativas e vínculos comunitários (LEMOS; LÉVY, 2010). É claro que não se pretende suprimir os locais físicos já existentes nem a sistemática da democracia representativa. O que se almeja consiste em tornar efetivo o conceito de cidadania apresentado por T. H. Marshall, como sendo uma soma dos direitos civis, políticos e sociais.

A internet emerge como um mecanismo apto a alterar a lógica de pensamento que observa no cidadão apenas a possibilidade de mais um voto em uma disputa eleitoral para determinado cargo instituído pela democracia representativa. Deveria tê-lo, em verdade, como um anseio, como a representação de uma necessidade que precisa ser atendida ou como a demonstração de uma vila, de um bairro, de uma cidade.

O que se almeja com a utilização da internet é uma aproximação entre os cidadãos e os Estados, de forma que a opinião popular seja levada em conta quando da tomada de decisões, e que cada indivíduo possa sentir que faz parte de um Estado, que suas demandas são consideradas e, posteriormente, atendidas. De acordo com Sustein

\footnotetext{
Convém ressaltar, no entanto, que, de acordo com a $7^{\mathrm{a}}$ edição da pesquisa TIC Domicílios Pesquisa sobre o Uso das Tecnologias da Informação e da Comunicação no Brasil, realizada pelo Comitê Gestor da Internet no Brasil (CGI.br), 45\% da população têm acesso ao computador no Brasil. Na área urbana, a presença é significativamente maior $(51 \%)$ do que na área rural (16\%). Cerca de quatro a cada dez municípios brasileiros possuem acesso à internet, o que representa $38 \%$ - é expressivo o crescimento, pois esse percentual, no ano de 2010 , era de $27 \%$. A penetração da internet nos domicílios brasileiros é maior na região Sudeste $(49 \%)$ e menor na região Nordeste (21\%). De acordo com dados fornecidos pela União Internacional de Telecomunicações, a proporção de $38 \%$ (de penetração da internet nos domicílios brasileiros) está abaixo das Américas (50\%), porém, acima dos Estados Árabes (26\%), da Ásia e Pacífico (25\%) e África (6\%). A Europa, por sua vez, apresenta contínuo crescimento desde 2005, registrando 34 pontos acima da média brasileira (CGI. BR, 2013).
} 
(2007), o grande desafio da atual sociedade globalizada e consumista reside em avaliar as novas tecnologias, incluindo a internet, questionando como elas afetam a cidadania em uma perspectiva ampla (civil, política e social), e não apenas o cidadão-consumidor.

Revela-se uma prática que tende a beneficiar os dois polos dessa relação, porque, ao exprimir a sua opinião e vê-la sendo efetivada pelo governo, o cidadão adquire maior confiança na própria democracia e naquela pessoa que o representa, deixando de ser um mero consumidor e passando a ser um cidadão atuante que fiscaliza e participa das decisões tomadas. Por outro lado, beneficia os governos, que conseguem atuar e executar obras e ações na sociedade, deixando de lado os interesses particulares.

Cabe nesse ponto salientar que, para Marques (2006), a internet não detém a capacidade de, isoladamente, resolver todos os problemas que circundam a atuação estatal, porque reunir a população para debater determinado assunto não significa que todos os indivíduos estão interessados na temática ou que a discussão alcançará as esferas representativas responsáveis por implantar os projetos públicos. A “[...] internet não viria no sentido de prejudicar a democracia, mas também não seria responsável por uma revolução em termos de compreensão desta forma de governo" (MARQUES, 2006, p. 182).

O que o autor quer dizer é que devem ser feitas ressalvas à internet enquanto esfera pública, porque, ao mesmo tempo em que não se pode negar que muitos debates só ocorrem em razão da existência dessa modalidade de comunicação, também não se pode desconsiderar que o ambiente digital está cercado de empresas que buscam apenas o lucro, não havendo qualidade no debate, ou que as discussões não serão levadas a sério pelas esferas do sistema político, justamente pela falta de comprometimento com as questões públicas.

Desse posicionamento do autor, pode-se afirmar que, em muitos casos, os mecanismos disponibilizados na internet servem muito mais para a deliberação, discussão e formação crítica dos cidadãos do 
que efetivamente para decisões que serão repassadas aos poderes competentes e, assim, implementadas.

Todavia, como se trata de uma temática relativamente nova e que ainda depende de maior discussão, não podem ser desconsideradas as alternativas que buscam aproximar os cidadãos do poder público, tentando atender às suas demandas e expectativas, a exemplo do que será abordado no próximo tópico.

\section{A experiência do Gabinete Digital que se inicia no estado do Rio Grande do Sul e se dissemina pelo Brasil}

Conforme foi visto, o espaço propiciado pela internet tende a reforçar o conceito de cidadania, aproximando a população dos governantes e deixando de lado a noção de cidadão como sinônimo de eleitor. O papel dos cidadãos nas democracias representativas não se resume a comparecer de quatro em quatro anos às urnas para a escolha dos representantes, pois a atuação cidadã compreende, retomando Marshall, aspectos civis e sociais que devem ser levados em conta e priorizados pelos indivíduos e governos.

Por isso, a internet tem se revelado um canal que, cada vez mais, permite o diálogo entre os cidadãos e os representantes. Abre-se um espaço para que os cidadãos participem da gestão pública, orientando a administração pública para a adoção de medidas que atendam efetivamente aos seus interesses e, ao mesmo tempo, fiscalizando os atos dos Estados ${ }^{4}$.

Criado pela ação estatal, o Gabinete Digital - uma iniciativa do Governo do Estado do Rio Grande do Sul - objetiva que os cidadãos se manifestem acerca das necessidades que devem ser incorporadas

4 Recentemente, foi aprovada a Lei de Acesso à Informação (Lei n. ${ }^{\circ}$ 12.527/2011), que visa, dentre outros objetivos, permitir maior acesso às informações e dados do governo. A título exemplificativo, no artigo $8^{\circ}$, há a previsão de que a Administração Pública deve promover, por conta própria, a divulgação das informações, independentemente de requisição dos cidadãos, dentre outras disposições (BRASIL, 2011). 
por políticas públicas do governo. Esse portal foi escolhido como parâmetro para a pesquisa de outros sites que também objetivam atrair a participação popular, através de um contato direto com os governantes, justamente por ser um local dinâmico e que vem sendo frequentemente utilizado pelo governo do Estado.

Conforme a própria descrição contida no site, o Gabinete Digital constitui-se em um "[...] canal de participação e diálogo entre governo e sociedade" (GABINETE DIGITAL, 2013a). O portal, que está vinculado à Secretaria Geral do Governo, tem como principal objetivo incorporar novas ferramentas de participação, proporcionando aos cidadãos influenciar na gestão pública e exercer maior controle sobre a atuação do Estado.

O site foi criado em maio de $2011^{5}$ e atualmente conta com as seguintes formas de interatividade: "Governador Responde", "Governador Escuta", "Governador Pergunta”, "Agenda Colaborativa” e "De olho nas obras - o governo faz, eu fiscalizo". Tais mecanismos detêm o condão de facilitar o acesso à informação pública e, consequentemente, um contato quase direto com o governador do estado.

No item "Governador Responde"6, o cibernauta pode enviar um questionamento diretamente ao governador do estado e há uma votação no site, realizada pelos próprios internautas, para eleger as perguntas em que há maior interesse na resposta. Podem ser respondidos também

5 Pela dinamicidade do meio em que está inserido o portal, a pesquisa realizada neste trabalho não teve por objetivo verificar se outros portais o precederam. A escolha recaiu na experiência gaúcha, conforme assinalado, por verificar-se a existência de um local que vem ganhando notoriedade por permitir um contato direto da população com o governo e por estar atento a temáticas recentes que demandam a oitiva da opinião popular.

6 Na página inicial desse item, há a menção de que: "Em 9 edições do Governador Responde, mais de 90 questões foram respondidas em vídeo pelo governador e mais de 25 mil votos foram recebidos. Agora a ferramenta entra em uma nova fase, passará por uma reestruturação técnica e metodológica. Durante esse período, todas as respostas enviadas até o momento serão respondidas gradualmente em texto. O recebimento de perguntas será retomado em 2013. Você pode continuar participando através das demais ferramentas. Exerça sua cidadania. Dúvidas ou sugestões podem ser enviadas para gabinetedigital@sgg.rs.gov.br" (GABINETE DIGITAL, 2013b). 
outros questionamentos que não necessariamente os mais votados, a critério do governador (GABINETE DIGITAL, 2013b).

As perguntas devem ser efetuadas a partir das temáticas sugeridas no site, quais sejam: acessibilidade, agricultura, combate à miséria, cultura, educação, energia, enfrentamento às calamidades climáticas, enfrentamento ao crack e às drogas, esporte, estradas, habitação, juventude, meio ambiente e saneamento, mulheres, petróleo, gás natural e polo naval, saúde, segurança pública, segurança no trânsito, tecnologia da informação etc. Depois de escolhido o tema, o internauta pode elaborar perguntas a partir do que já foi sugerido por outros internautas, ou então formular um novo questionamento. Destaca-se que no próprio site são sugeridas dicas para o questionamento:

Escolhe o tema que mais se encaixa no questionamento que você deseja fazer e elabore uma pergunta direta e objetiva, explicando um pouco o contexto envolvido no seu questionamento. Assim que você enviar sua pergunta, inicie uma campanha para que ela tenha muitos votos. (GABINETE DIGITAL, 2013b).

Quanto à possibilidade de realização de uma campanha sobre o questionamento, pode-se compartilhar pelas redes sociais ou via e-mail. Para enviar o questionamento, é necessário um prévio cadastro no site, criando login e senha. A pergunta, após enviada, será analisada por uma equipe do Gabinete Digital, e se estiver de acordo com a Política de Contribuição ${ }^{7}$ e os Termos de Uso ${ }^{8}$ do site, será aprovada.

7 "Todas as contribuições enviadas para o Gabinete Digital passarão por mediação. As ferramentas Governador Pergunta e Governador Responde não permitem identificação do usuário. A metodologia privilegia o conteúdo da contribuição para que não haja desvios. Fica resguardado o direito de edição de mensagens encaminhadas contendo nome, apelido ou qualquer outra forma de identificação" (GABINETE DIGITAL, 2013c).

8 "Este documento descreve os termos de uso do site Gabinete Digital, cuja aceitação plena e integral é requisito para todos os seus participantes. Ele inclui, além dos termos gerais, termos de limitação de responsabilidade, a política de privacidade e confidencialidade, a licença de livre uso do conteúdo e as informações de como reportar violações" (GABINETE DIGITAL, 2013d). 
Interessante referir que, nesse item ("Governador Responde"), o objetivo central não é apenas escolher o questionamento mais votado e respondê-lo, mas também "[...] pautar o assunto internamente e oferecer um retorno, seja na criação de uma política pública, no encaminhamento do debate a um departamento específico ou no esclarecimento aos cidadãos sobre o que vem sendo feito em determinada área" (WU, 2013, p. 13).

No item "Governador Escuta", há a possibilidade de audiências públicas, a serem transmitidas ao vivo, abertas à participação on-line do cidadão (cujas perguntas são respondidas imediatamente, durante as audiências), com a presença de especialistas. Por exemplo, "Plano Estadual da Cultura", "Novo modelo de pedágios", "Lançamento consulta pública sobre trânsito", "Copa do Mundo 2014", "O que dizem as ruas?" (referente às recentes manifestações populares que vem ocorrendo em todo o país), entre outras (GABINETE DIGITAL, 2013e).

Quanto ao item "Governador Pergunta", incluído em recente reformulação do site, trata-se de um espaço em que o próprio governador solicita a colaboração dos internautas para a discussão de temas de interesse público, buscando subsídios para o desenvolvimento de políticas públicas do estado. O primeiro questionamento tratou sobre a saúde pública ("O que podemos fazer para melhorar o atendimento da saúde pública?") e o segundo referiu-se ao trânsito ("Como governo e sociedade podem, juntos, promover a paz no trânsito?"). De acordo com o site, foram registrados 240.516 votos e 2.111 propostas, o que representa "[...] um salto de $100 \%$ no comparativo com a primeira edição do projeto, em 2011, quando os gaúchos elegeram as 50 prioridades para melhorar a saúde pública no estado" (GABINETE DIGITAL, 2013f).

Ainda de acordo com o descrito no portal, nessa edição do "Governador Pergunta", iniciada em 09 de outubro de 2012 e encerrada em 16 de novembro de 2012, foi submetida à consulta popular o Plano 
Estadual de Segurança no Trânsito para a década 2011-2020. A população teve trinta dias para enviar e votar nas próprias ideias sobre o tema e nas ações previstas no referido plano (GABINETE DIGITAL, 2013f).

Depois de recebidas as contribuições, muitos internautas podem se questionar sobre o destino dessa colaboração. De acordo com o site, dez propostas escolhidas na votação, sendo duas de cada área (educação, segurança viária, comunicação, legislação e saúde), foram adotadas como prioridade pelo governo do estado até o ano de 2014 (GABINETE DIGITAL, 2013f).

Salienta-se a importância da participação dos cidadãos, que não deve encerrar-se com a votação de temáticas de importância, fiscalizando as ações do governo, com a finalidade de verificar se as demandas estão sendo atendidas ou se é um recurso sem utilidade prática.

A consulta pública não se deu apenas via internet. Também foram realizadas consultas locais, palestras e outras atividades que tiveram contato direto com a população, especialmente a mais vulnerável, que não possui acesso à rede: "Além da votação direta no site, duas vans percorreram milhares de quilômetros no interior e na Região Metropolitana, divulgando a consulta e recebendo contribuições." (GABINETE DIGITAL, 2013f).

Por mais que haja um significativo aumento no número de usuários e acessos à internet, ainda se faz necessário o contato pessoal e direto com os cidadãos, bem como a utilização dos meios de comunicação tradicionais (televisão, rádio, jornal) para a difusão dessas possibilidades de participação on-line.

9 No portal, também consta uma explicação sobre as razões da escolha do tema: "A Organização das Nações Unidas (ONU) declarou o período de 2011 a 2020 como a Década Mundial de Ações de Segurança no Trânsito, com o objetivo de reduzir pela metade as mortes no trânsito. Em junho de 2011 foi instituído o Comitê Estadual de Mobilização pela Segurança no Trânsito responsável pela criação do Plano Estadual de Segurança no Trânsito para a década 2011-2020." (GABINETE DIGITAL, 2013f). 
Já o item "Agenda Colaborativa" constitui-se na transferência, durante um dia do mês, do governo do estado para uma cidade do interior, com o objetivo de aproximação das comunidades e maior conhecimento das demandas específicas de cada localidade. Através da ferramenta, a própria população pode indicar temáticas a serem discutidas no evento.

Verifica-se a nítida relação existente entre o ambiente físico e o digital, pois a primeira etapa do processo é constituída por ações on-line, em que os cidadãos enviam as contribuições, as quais são organizadas e atualizadas pelo portal. Em um segundo momento, realiza-se a ação presencial, com o deslocamento do governador, em uma tentativa de visualização das carências da localidade. Atualmente, conforme informação do próprio site, o recurso está suspenso, dando-se prioridade ao aplicativo "Governador Pergunta" (GABINETE DIGITAL, 2013g).

Ainda que a internet permita uma infinidade de atividades a serem realizadas, possibilitando dinamicidade nas ações e, assim, maior atração dos cidadãos, ainda se faz necessário o contato físico, uma vez que o acesso à internet no Brasil ainda não alcança a população brasileira como um todo.

Em junho de 2013, foi lançado o item "De olho nas obras - o governo faz, eu fiscalizo"10. No site, há a indicação de sete obras que vem sendo executadas pelo governo estadual, e o cibernauta pode escolher uma para acompanhamento, informando-se sobre o andamento através de imagens, cronograma de entrega etc. O cidadão cadastra-se tanto para receber as atualizações referentes às obras (através de e-mail

10 "O Gabinete Digital é uma das experiências mais exitosas de governo aberto da América Latina, segundo a Red Gobierno Abierto, da Argentina. A iniciativa recebeu o Premio Gobierno Abierto Puntogov Asaec, em cerimônia no Senado de La Nación, em Buenos Aires, nesta quinta-feira, 6. No total, 55 iniciativas das Américas se inscreveram para concorrer ao prêmio, das quais oito foram selecionadas. As experiências ganhadoras foram incluídas em um e-book de distribuição gratuita para compartilhar práticas e conhecimento sobre governo aberto. [...] A ferramenta de monitoramento de obras públicas que está sendo desenvolvida e que será lançada pelo Gabinete Digital, ainda em junho, chamou a atenção. Para o presidente da Fundación Sociedades Digitales, Fabricio Vagliente, a iniciativa de abrir os dados de setor tão delicado do orçamento demonstra o efetivo interesse do Governo em promover a transparência." (GABINETE..., online, 2013). 
ou contas no Facebook e Twitter) como para fiscalizar o andamento, enviando fotos, comentários, dúvidas ou críticas. A cada trinta dias (semelhante, portanto, ao item "Governador Responde"), o governador manifesta-se, através de vídeo, sobre as obras mais acessadas e fiscalizadas (GABINETE DIGITAL, 2013i).

Ao clicar nas obras, abre-se uma descrição com informações básicas, que incluem uma síntese do projeto, o andamento da obra (em porcentagem), a empresa executora, a data de início e previsão de término, valor total e imagens atuais (GABINETE DIGITAL, 2013i).

Ademais, diante das manifestações recentes que ocorreram no Brasil sobre a necessidade de se fazer uma reforma política, o governo inaugurou no site do Gabinete Digital, no dia 03 de julho de 2013, uma consulta popular sobre o tema. A consulta foi constituída por duas perguntas: na primeira, o cidadão tinha a opção de escolher se a reforma política deve ser feita pelo Congresso Nacional ou se deve ser instaurada uma Câmara Constituinte exclusiva; já a segunda buscava identificar as prioridades de mudanças que devem ocorrer no sistema político (GABINETE DIGITAL, 2013j).

Descritas as principais características do portal, verifica-se que há uma intensa atuação do governo para atrair a participação popular, inclusive sobre temas recentes e que têm mobilizado a população de maneira presencial. Por isso, interessa mencionar que a inovadora ideia do Governo do Estado do Rio Grande do Sul já está sendo seguida por outros estados, municípios e, inclusive, por um instituto federal. A pesquisa para sistematizar e mapear os lugares que adotaram iniciativas semelhantes partiu de um artigo explicativo do Secretário-Geral do Governo e Coordenador-Geral do Gabinete Digital, Vinicius Wu (WU, 2013).

No artigo, citam-se alguns municípios e estados que mantêm contato com o Gabinete Digital, com a finalidade de adoção de experiências similares. Partindo desse texto, realizou-se, durante o mês de junho de 2013, uma pesquisa nos sites das prefeituras e governos estaduais citados pelo referido artigo, com o objetivo de encontrar tais 
projetos. Em razão disso, trata-se de pesquisa não exaustiva, que buscou verificar se a iniciativa vem sendo seguida por outros locais.

Foram encontradas nove iniciativas, que podem ser divididas em quatro categorias, as quais serão detalhadas a seguir: a) assemelham-se ao Gabinete Digital do Estado do Rio Grande do Sul por trazerem formas de interatividade do governo com a população; b) há interatividade entre os cidadãos e o governo, mas a iniciativa é específica e temporária; c) a interatividade ocorre de forma presencial e os sites detêm apenas papel auxiliar; d) não há interatividade entre os governantes e a sociedade.

2.1 Iniciativas que se assemelham ao Gabinete Digital do Estado do Rio Grande do sul por haver interatividade entre sociedade e governo

Em 23 de abril de 2013, foi lançado em Caruaru¹1, município localizado no estado de Pernambuco, um portal também intitulado "Gabinete Digital". Da mesma forma que a iniciativa gaúcha, é um canal de diálogo entre a gestão do município e a sociedade civil, que apresenta como objetivo principal "[...] incorporar novas ferramentas de participação, onde o cidadão possa tornar a gestão cada vez mais colaborativa e participativa, a partir de mecanismos virtuais, fortalecendo valores democráticos" (CARUARU, online, 2013).

Nesse portal, a participação ocorre em dois espaços: "Prefeito Responde" e "Agenda Colaborativa". No primeiro, a população efetua os questionamentos, à semelhança da experiência gaúcha, sendo também necessário o prévio cadastro, e a resposta é conferida ao questionamento mais votado, através de um vídeo. No segundo, a população pode interferir diretamente na agenda do prefeito, solicitando a sua presença em determinada comunidade, propondo temas para debate - Programa Prefeitura nas Ruas (GABINETE DIGITAL CARUARU, 2013).

11 De acordo com o Censo de 2010, realizado pelo Instituto Brasileiro de Geografia e Estatística (IBGE), o município conta com 314.912 habitantes (IBGE, 2013). 
A outra iniciativa refere-se ao Instituto Federal Fluminense (IFF) e se intitula "Gabinete Digital", assemelhando-se à experiência gaúcha por contar com o item "Pergunte ao Reitor", nos mesmos moldes do governo gaúcho. O questionamento é enviado através do site, havendo a possibilidade de mobilização de outros internautas para apoiarem o assunto que, ao final de quinze dias, será respondido com um vídeo $^{12}$ do reitor do Instituto. Assim como o site do governo gaúcho, é necessário fazer um login com senha para efetuar os questionamentos (INSTITUTO..., online, 2013).

2.2 Iniciativa específica e temporária em que há interatividade entre sociedade e governo

No município do Rio de Janeiro, foi criado um projeto piloto intitulado "Melhora Comunidade", desenvolvido pelo Centro de Tecnologia e Sociedade (CTS) da Escola de Direito da Fundação Getúlio Vargas (FGV), em parceria com o Banco Mundial e a Fundação Ford. A iniciativa contou com 658 participantes, moradores da Cidade de Deus, zona oeste do Rio de Janeiro, que detinham acesso restrito ao site (www. melhoracomunidade.com.br), e utilizou o método comparativo, pois foram apresentadas duas alternativas para os indivíduos escolherem a que melhor lhes favorecia (PESQUISADORES, online, 2013).

O projeto, que colheu dados de três principais pontos - percepção da segurança pública, problemas vivenciados pela comunidade (demandas de políticas públicas) e o consumo de mídia e informação na comunidade -, foi realizado em parceria com lan houses locais. Isso permitiu o acesso dos moradores à internet e demonstrou a viabilidade da realização de pesquisas com a utilização da internet, mesmo em locais excluídos digitalmente (PESQUISA, online, 2013) ${ }^{13}$.

\footnotetext{
12 Ao analisar o site, verifica-se que há questionamentos que foram respondidos apenas de forma escrita.

13 Alguns dados obtidos com a pesquisa podem ser encontrados em: <http://direitorio.fgv.br/ node/2507>. Acesso em: 03 jul. 2013.
} 
2.3 Sites atuam de forma auxiliar aos debates que ocorrem presencialmente

Em São Paulo, a iniciativa "\#existediálogoemSP”, da Secretaria Municipal de Cultura, objetiva a construção colaborativa de políticas públicas referentes ao fortalecimento da cultura, através do diálogo. O projeto, que se constitui, de acordo com a descrição contida no site, em um espaço aberto, presencial e virtual, pretendia, durante o ano de 2013, a criação de um gabinete aberto e digital, baseado em processos de diálogo permanente; a instalação de um novo Conselho Municipal de Cultura; a elaboração de um Plano Municipal de Cultura para atuação nos próximos dez anos; bem como a incorporação das demandas públicas da cultura na revisão do Plano Diretor do município (SÃO PAULO, 2013).

Pelo que se depreende da análise do site, foram realizados três encontros ao longo do ano, no Centro Cultural São Paulo, acompanhados de manifestações teatrais, musicais, dentre outros, sendo transmitidos ao vivo pelo próprio site. Essa construção paulista demonstra uma utilização ainda incipiente da internet, uma vez que faz do meio apenas o transmissor dos eventos que vêm ocorrendo, sem promover o contato direto entre cidadãos e governo, conforme visto na experiência gaúcha do Gabinete Digital.

Em Porto Alegre, há o "Observa POA", o Observatório da Cidade de Porto Alegre, que disponibiliza informações georreferenciadas sobre o município, com a finalidade de reforçar a identidade do local, promovendo a aproximação entre as pessoas que residem nas comunidades. Também disponibiliza indicadores capazes de qualificar a gestão participativa através de orçamento participativo, conselhos municipais e governança sólida local, sob três perspectivas: social (impacto na qualidade de vida); gestão (impacto na eficácia, transparência e descentralização da gestão municipal); e política (impactos no desenvolvimento democrático e na cidadania) (POA, online, 2013).

Pelo que se percebe a partir de uma rápida observação do site, há grande destaque para o orçamento participativo, que desde 1989 
vem sendo realizado na capital gaúcha. Consiste em um processo dinâmico de decisão da população sobre os investimentos que devem ser prioridades para a prefeitura. Depreende-se da análise do site específico do orçamento participativo que a internet não é usada para a deliberação, mas para prover informações gerais sobre o que vem sendo discutido, bem como sobre a execução e o andamento de obras e serviços. Ou seja, a internet funciona como uma ferramenta auxiliar ao orçamento participativo tradicional (ORÇAMENTO PARTICIPATIVO, 2013).

\subsection{Não há interatividade entre sociedade e governo}

No município de São Paulo, há o "Programa de Metas da Prefeitura de São Paulo", que apresenta as cem metas para o desenvolvimento da cidade até o ano de 2016. O site foi criado para facilitar a análise das propostas e o acompanhamento de projetos de lei, licitações e orçamentos, cujas metas foram divididas em eixos temáticos, articulações territoriais e conclusão ou não das políticas públicas. O contato, em síntese, ocorre através de e-mails, o que dificulta a interatividade com o governo e entre os próprios cidadãos. A forma de participação mais ativa no site é através do item "Adotar uma Meta", em que há a possibilidade de escrever no blog do projeto e reunir informações sobre as obras que vêm sendo desenvolvidas (PRESTANDO CONTAS, 2013).

A cidade de Bragança Paulista, no interior do estado de São Paulo, lançou a iniciativa em fevereiro de 2013, com semelhante nome ao da experiência gaúcha: Gabinete Digital Bragança Paulista. O site é considerado o espaço oficial de comunicação direta entre a prefeitura e a população, possuindo como missão promover a democracia participativa, aproximar o poder público da população, colaborando para a construção de um governo democrático e popular. A interatividade ocorre mediante a leitura e o compartilhamento de informações prestadas pelo governo, pelo saneamento de dúvidas da população ou, ainda, pelo devido encaminhamento de reclamações e denúncias. No entanto, a única forma de contato encontrada no site consiste no envio 
de mensagens à prefeitura por meio de uma caixa de texto (BRAGANÇA PAULISTA, 2013, online).

O governo da Bahia, através da Secretaria da Administração, lançou o blog intitulado "Gestão em Debate" com a finalidade de dividir com os servidores e demais setores da sociedade a responsabilidade de administração do estado: "O objetivo é promover, com a troca de opiniões, o entendimento de que a melhoria das condições da atuação da máquina pública não se dá de outra maneira senão pela pluralização de ideias e propostas que resultem no seu amadurecimento." (BAHIA, online, 2013). Para entrar em contato com a administração, são fornecidos dois endereços de e-mails - blogdegestão@saeb.ba.gov. br e gestaoemdebatesaeb@gmail.com. Isso demonstra que, por mais salutar que a iniciativa se revele, há quase nenhuma interatividade com a população.

Por fim, a ideia da prefeitura de Guarulhos, intitulada "Gabinete Digital de Guarulhos", apresenta vídeos em que o prefeito faz esclarecimentos, trata de projetos, políticas públicas etc. Não se visualizou, no entanto, a possibilidade de participação popular no site, demonstrando que o espaço constitui-se em um local de publicidade e manifestação unilateral, da prefeitura, sem haver contribuições da sociedade (GUARULHOS, 2013, online).

Essas quatro iniciativas - município de São Paulo, Guarulhos, Bragança Paulista e estado da Bahia - não apresentaram mecanismos para interatividade e contato direito entre os cidadãos e os governantes. Tratam-se, portanto, de mecanismos que apresentam conteúdo estático, sem a possibilidade de retorno imediato aos questionamentos efetuados, distanciando-se das formas proporcionadas pelo site do Gabinete Digital do Estado do Rio Grande do Sul, utilizado como parâmetro para a pesquisa.

\section{Conclusão}

Depreende-se da pesquisa realizada que há a necessidade de repensar o conceito de cidadão, o qual não pode mais ficar restrito 
apenas à condição de detentor de direitos políticos. A internet revelase um meio de comunicação dinâmico, de fácil acesso e que tem sido largamente difundido, permitindo formas de comunicação simplificadas e que podem contar com a inserção de áudio, vídeo e outras ferramentas que atraiam a atenção do público.

Verifica-se que há interesse dos governos em ouvir as necessidades e carências da população, constatando-se que a experiência do Gabinete Digital do Estado do Rio Grande do Sul vem sendo seguida por outros lugares. Há iniciativas que objetivam atrair a participação popular, mas ainda predomina a existência de mecanismos que se mantêm estáticos, não permitindo interatividade do governo com os cidadãos e nem entre os próprios cidadãos.

Não se pode desconsiderar que tais ações são ainda incipientes e, talvez por essa razão, a maioria dos sites apresenta conteúdo fechado, com pouco acesso, apenas com a finalidade de demonstrar o que vem sendo realizado pelo governo. Em muitos casos, verifica-se que a utilização da internet tem o condão de fazer propaganda e demonstrar que há interesse do governo na oitiva da população, no entanto, sem disponibilizar recursos para essa interação.

O que não se pode negar, todavia, é a inserção da internet como um local em que há a possibilidade de organização dos indivíduos, de promoção de debates e de construção colaborativa de ideias e políticas públicas. Evidencia-se, assim, a construção da cibercidadania no Brasil, tornando política a participação dos indivíduos na internet e demonstrando que a atuação destes detém a capacidade de influenciar na tomada de decisão dos governantes.

Como o acesso à rede ainda não alcança a maioria da população brasileira, faz-se necessária a utilização de mecanismos alternativos - como a parceria com lan houses, no caso referente à comunidade Cidade de Deus, no Rio de Janeiro - e a complementação do que é discutido no site por ações presenciais. Isso demonstra que, no atual estágio de utilização e difusão da internet no Brasil, é imperiosa a presença física, utilizando-se dos demais meios de comunicação para 
que as ações realizadas on-line alcancem também a população que não detém acesso à rede.

Tais ações ainda são relativamente novas e demandam maior estudo e atenção, seja pela população, para verificar se as demandas efetivamente estão tornando-se prioridades na adoção de políticas públicas, seja pela academia, a fim de verificar se tais empreendimentos não detêm cunho eleitoreiro e "funcionam" apenas em períodos eleitorais, quando se busca maior contato com a população.

\section{Referências}

BAHIA. Prefeitura Municipal. Gestão em debate. Disponível em: <http:// www.gestaoemdebate.saeb.ba.gov.br/>. Acesso em: 22 ago. 2013.

BRAGANÇA PAULISTA. Prefeitura Municipal. Gabinete digital. Disponível em: <http://braganca.sp.gov.br/v2/gabinete-digital/>. Acesso em: 22 ago. 2013.

BRASIL. Constituição da República Federativa do Brasil: de 05 de outubro de 1988. Brasília, DF: Senado Federal, 1988. Disponível em: <http://www.planalto.gov.br/ccivil_03/constituicao/ ConstituicaoCompilado.htm>. Acesso em: 15 ago. 2013.

. Lei $\mathrm{n}^{\circ}$ 12.527/2011 de 18 de novembro de 2011. Regulamenta o acesso a informações previsto no inciso XXXIII do artigo $5^{\circ}$, no inciso II do $\S 3^{\circ}$ do artigo 37 e no $\S 2^{\circ}$ do artigo 216, da Constituição Federal; altera a Lei $n .{ }^{\circ} 8.112$, de 11 de dezembro de 1990; revoga a Lei $n .^{\circ}$ 11.111, de 05 de maio de 2005, e dispositivos da Lei n. ${ }^{\circ} 8.158$, de 08 de janeiro de 1991; e dá outras providências. Brasília, DF, 2011. Disponível em: <http://www.planalto.gov.br/ccivil_03/_ato2011-2014/2011/lei/ I12527.htm>. Acesso em: 20 ago. 2013.

CARUARU. Prefeitura Municipal. Gabinete digital. Disponível em: <http://www.gabinetedigitalcaruaru.com.br/>. Acesso em: 22 ago. 2013.

CASTELLS, Manuel. A galáxia da Internet: reflexões sobre a internet, os negócios e a sociedade. Rio de Janeiro: Zahar, 2003. 
A sociedade em rede: a era da informação: economia, sociedade e cultura: São Paulo: Paz e Terra, 1999. v. 1.

COMITÉ GESTOR DA INTERNET NO BRASIL. Pesquisa sobre o uso das tecnologias de informação e comunicação no Brasil. Disponível em: <http://op.ceptro.br/cgi-bin/indicadores-cgibr-2010?pais=brasil\&est $\mathrm{ado}=\mathrm{rs} \&$ academia $=$ academia\&age $=\mathrm{de}-16$-a-24-anos\&education=superi or\&purpose=pesquisa-academica>. Acesso em: 20 ago. 2013.

DALLARI, Dalmo de Abreu. Elementos de teoria geral do Estado. 29. ed. São Paulo: Saraiva, 2010.

GABINETE DIGITAL. Disponível em: <http://gabinetedigital.rs.gov.br/>. Acesso em: 22 ago. 2013a.

. Governador responde. Disponível em: <http://gabinetedigital. rs.gov.br/govresponde/>. Acesso em: 22 ago. 2013b.

.Política de Contribuição. Disponívelem:<http://gabinetedigital. rs.gov.br/pages/politica-de-contribuicao/>. Acesso em: 22 ago. 2013c.

. Termos de uso. Disponível em: <http://gabinetedigital.rs.gov. br/pages/tos/>. Acesso em: 22 ago. 2013d.

. Governador Escuta. Disponível em: <http://gabinetedigital. rs.gov.br/govescuta/>. Acesso em: 22 ago. 2013 e.

. Governador Pergunta. Disponível em: <http://gabinetedigital. rs.gov.br/govpergunta/resultados/2012/>. Acesso em: 22 ago. $2013 f$.

Agenda Colaborativa. Disponível em: <http://antigo. gabinetedigital.rs.gov.br/especial.php?pagina=agenda>. Acesso em: 22 ago. $2013 \mathrm{~g}$.

. De olho nas obras. Disponível em: <http://gabinetedigital. rs.gov.br/monitore/>. Acesso em: 22 ago. 2013 i.

Governo gaúcho lança consulta sobre reforma política. Disponível em: <http://gabinetedigital.rs.gov.br/post/governo-gaucholanca-consulta-sobre-reforma-politica/>. Acesso em: 22 ago. 2013j.

GABINETE Digital Ganha Prêmio Internacional de Governo Aberto. Gazeta do Sul, Rio Grande do Sul, 2013. Disponível em: <http:// 
www.gaz.com.br/noticia/409993-gabinete_digital_ganha_premio_ internacional_de_governo_aberto.html>. Acesso em: 22 ago. 2013h.

GUARULHOS. Prefeitura Municipal. Gabinete digital de Guarulhos. Disponívelem:<http://www.guarulhos.sp.gov.br/index.php?option=com content\&view=article\&id=11051\&Itemid=1461>. Acesso em: 22 ago. 2013.

INSTITUTO BRASILEIRO DE GEOGRAFIA E ESTATÍTICA - IBGE. Caruaru - PE. Dados básicos. Disponível em: <http://www.ibge.gov.br/ cidadesat/painel/painel.php?codmun=260410\#>. Acesso em: 22 ago. 2013.

INSTITUTO FEDERAL FLUMINENSE. Gabinete digital. Disponível em: <http://gabinetedigital.iff.edu.br/iff/>. Acesso em: 22 ago. 2013.

LEMOS, André; LEVY, Pierre. O futuro da internet: em direção a uma ciberdemocracia. 2. ed. São Paulo: Paulus, 2010.

LÉVY, Pierre. Cibercultura. São Paulo: Editora 31, 1999.

MARQUES, Francisco Paulo Jamil Almeida. Debates políticos na internet: a perspectiva da conversação civil. Opinião pública, Campinas, v. 12, n.1, p. 164-18, abr./mai, 2006. Disponível em: <http://academia.edu/424436/ Debates_Politicos_na_Internet_A_perspectiva_da_conversacao_civil_ Political_Debates_on_the_Internet_The_Idea_of_Civic_Conversation>. Acesso em: 01 ago. 2013.

MARSHALL, T. H. Cidadania, classe social e status. Rio de Janeiro: Zahar, 1967. Disponível em: <http://www.todosnos.unicamp.br:8080/ lab/acervo/capitulos/MARSHALL \%2CT. $\% 20 \mathrm{H} . \% 20$ Cidadania $\% 20$ e $\% 20$ classe\%20social_p.\%2057-\%20114..doc/view>. Acesso em: 22 ago. 2013.

OBSERVATÓRIO DA CIDADE DE PORTO ALEGRE.. Observapoa. Disponível em: <http://www.observapoa.com.br/default.php>. Acesso em: 22 ago. 2013.

PESQUISA do CTS-FGV usa a internet para medir percepção da upp entre jovens na cidade de Deus. Disponível em: <http://direitorio.fgv.br/ node/2507>. Acesso em: 22 ago. 2013. 
PESQUISADORES da FGV desesnvolvem modelo de pesquisa para área social. Disponível em: <http://www.rio.rj.gov.br/web/ipp/ exibeconteudo?article-id=3318307> . Acesso em: 22 ago. 2013.

PORTO ALEGRE. Prefeitura Municipal.Orçamento participativo. Disponível em: <http://www2.portoalegre.rs.gov.br/op/>. Acesso em: 22 ago. 2013.

PRESTANDO Contas. Disponível em: <http://www.prestandocontas. org/>. Acesso em: 22 ago. 2013.

SANTOS, Boaventura de Sousa. Os processos da globalização. In: SANTOS, Boaventura de Sousa (Org.). A globalização e as ciências sociais. 3. ed. São Paulo: Cortez, 2011.

SÃO PAULO. Secretaria Municipal de Cultura de São Paulo. \#existediálogoemSP. Disponível em: <http://www.centrocultural. sp.gov.br/existedialogoemsp/>. Acesso em: 22 ago. 2013.

SEN, Amartya. Ideia de justiça. Tradução de Denise Bottmann e Ricardo Doninelli Mendes. São Paulo: Companhia das Letras, 2011.

SILVA, José Afonso da. Curso de direito constitucional positivo. 32. ed. Malheiros: São Paulo, 2009.

SILVA, Marco. Seminário discute inclusão digital e cibercidadania. Disponível em: <http://www.anj.org.br/pje/seminario-discute-inclusaodigital-e-cibercidadania>. Acesso em: 22 ago. 2013.

SUNSTEIN, Cass. Republic.com 2.0. Princeton: University Press, 2007.

WU, Vinicius. Gabinete Digital: metodologias inovadoras em consultas públicas on-line. In: CONGRESSO DE GESTÃO PÚBLICA - CONSAD, 5., 2013. Brasília. Anais eletrônicos ... Brasília, 2013. Disponível em: <http://www.gestaoemdebate.saeb.ba.gov.br/wp-content/ uploads/2013/05/074.pdf>. Acesso em: 22 ago. 2013.

Recebido em: 28/08/13

Aprovado em: 19/17/14 